\title{
The effect of sample and comparison ratio schedules on delayed matching to sample in the pigeon
}

\author{
DONALD M. WILKIE and MARCIA L. SPETCH \\ University of British Columbia, Vancouver, British Columbia, Canada V6T IW5
}

\begin{abstract}
In Experiment 1, three food-deprived pigeons received trials that began with red or green illumination of the center pecking key. Two or four pecks on this sample key turned it off and initiated a 0 - to 10 -sec delay. Following the delay, the two outer comparison keys were illuminated, one with red and one with green light. In one condition, a single peck on either of these keys turned the other key off and produced either grain reinforcement (if the comparison that was pecked matched the preceding sample) or the intertrial interval (if it did not match). In other conditions, 3 or 15 additional pecks were required to produce reinforcement or the intertrial interval. The frequency of pecking the matching comparison stimulus (matching accuracy) decreased as the delay increased, increased as the sample ratio was increased, and decreased as the comparison ratio was increased. The results of Experiment 2 suggested that higher comparison ratios adversely affect matching accuracy primarily by delaying reinforcement for choosing the correct comparison. The results of Experiment 3, in which delay of reinforcement for choosing the matching comparison was manipulated, confirmed that delayed reinforcement decreases matching accuracy.
\end{abstract}

A controlling relationship between a stimulus and a response exists if responding changes when the stimulus is presented. If such a relationship occurs only when another stimulus is presented, the control is of a conditional variety. The two stimuli in conditional control procedures may or may not temporally overlap. When they do, the procedure is often called "conditional discrimination," when they do not, "memory."

Delayed matching to sample (DMTS) is one conditional control procedure in which the stimuli do not temporally overlap [see Wilkie and Wilson (1977), for example, for a discussion of others]. In DMTS, one stimulus (the sample) is presented and followed after a delay by two other (comparison) stimuli, one of which is identical to the preceding sample. Responding to the comparison stimulus that matches the sample is reinforced.

The degree of conditional control in the DMTS procedure arranged for pigeons, as measured by the frequency of pecking the matching comparison, is influenced by the manner in which events in DMTS are scheduled. The degree of conditional control is influenced by the schedule according to which samples are produced (Maki, 1975), the schedule by which responding to the sample produces the delay interval

This research was supported by National Research Council of Canada Grant A8353. M. Gordon assisted with testing the subjects. Reprints may be obtained from Donald M. Wilkie, Department of Psychology, University of British Columbia, Vancouver, Canada V6T IW5. and comparison stimuli (Maki, Gillund, Hauge, \& Siders, 1977; Roberts, 1972; Sacks, Kamil, \& Mack, 1972), and the schedule according to which pecking the matching comparison is reinforced with food (e.g., Ferster, 1960).

Maki (1975), using a variant of the DMTS procedure, found that the degree of conditional control was lower when pecking a white key produced colored samples according to a variable-interval $7.5-\mathrm{sec}$ schedule than when these were produced by a fixedratio 1 schedule. Maki et al. (1977), again using a variant of DMTS, first arranged that pecking the samples produced the comparison stimuli according to a fixed-ratio 10 schedule. They next arranged that pecking one sample was extinguished (did not produce the comparison stimuli). When pecking this sample again produced the comparison stimuli, the degree of conditional control was greatly reduced. Roberts (1972) and Sacks et al. (1972) found that the frequency of pecking the matching comparison increased as the number of pecks required to turn off the sample and produce the delay and comparison stimuli was increased. Ferster (1960) reported that the frequency of pecking the matching comparison increased when reinforcement for pecking the matching comparison was available on only about $5 \%$ rather than $100 \%$ of the trials. It should be noted that Ferster's finding was not confirmed in an indirect replication by Nevin, Cumming, and Berryman (1963). Nevin et al. found, as well, that matching accuracy was higher under variable-ratio than under fixed-ratio schedules. This effect does not appear to hold, however, when these 
schedules are part of second-order (Kelleher, 1966) schedules (cf. Boren, 1973).

As far as is known, the effect of different schedules of comparison stimuli termination on matching accuracy has not been systematically studied [although there has been one recent study of the effects of comparison schedules on choosing the odd stimulus by Lydersen, Perkins, and Chairez (1977)]. In all studies, only a single response to the comparison stimuli has been required. The main purpose of the present research was to investigate the effects of requiring more than one peck at the comparison stimuli to terminate these stimuli and produce reinforcement and/or the intertrial interval. Extent theories of DMTS performance (e.g., Roberts \& Grant, 1976) seem to make no predictions as to the effects of different schedules of comparison stimuli termination.

\section{EXPERIMENT 1}

The number of pecks on the comparison keys required to produce reinforcement (when the matching comparison was pecked) or the intertrial interval (when the odd comparison was pecked) was varied. To check for the possibility of a delay by schedule interaction, the schedule was varied at each of several delay values. An attempt also was made to replicate Roberts' (1972) and Sacks et al.'s (1972) sample schedule results.

There are two basic ways of arranging schedules of comparison stimuli termination. Under one, both comparison stimuli terminate at the same time after $\mathbf{n}$ responses on one key. Under this procedure, it is the $\mathrm{n}^{\text {th }}$ response that determines if a trial will end in reinforcement. Under the other procedure, the first response to one comparison terminates the other; then $n-1$ responses on the first-pecked comparison produces reinforcement or the intertrial interval. Under this procedure, it is the first response that determines if a trial will end in reinforcement. Because the former procedure permits key switching and hence potential problems of nonindependence of responding to the two comparison stimuli (cf. Catania, 1966), the second procedure was used in the present studies.

\section{Method}

Subjects. Three adult King pigeons were maintained at about $85 \%$ of free-feeding weight by mixed grain obtained during and after experimental sessions. The birds had unlimited access to water and grit in their home cages. The birds had varied experimental histories; none, however, had participated previously in DMTS experiments.

Apparatus. One wall of a Tech Serv, Inc., Model PS-004 lightproof, sound-attenuating chamber contained three clear plastic pecking keys arranged in a row, a grain feeder, and three Industrial Electronics Engineers' Series 10 projectors. The projectors, which were mounted behind the keys, illuminated the keys during trials with uniform fields of red and green light. The feeder was located directly below the center key. The feeder, when operated, permitted 5 -sec access to mixed grain illuminated by a lamp. The chamber was dark except for the projector and feeder light. A fan ventilated the chamber and provided a masking noise. Experimental conditions and data recording were implemented by Digibit solid-state and electromechanical circuits.

Procedure. All birds received experimental sessions at approximately the same time each day, 7 days per week, for the duration of the experiment. As all birds had previous experimental experience, no preliminary feeder or keypeck training was necessary. Each subject received 10 preliminary training sessions in which matching behavior was established.

During the experiment proper, sessions normally consisted of 60 DMTS trials, separated by 30 -sec intertrial intervals during which the chamber was dark and keypecking had no consequences. In each session, red and green served as sample stimuli equally often. The right-left location of red and green and matching and odd comparison stimuli was randomized within the constraint that each of the four types of trials occur equally often. During the first 10 sessions, four pecks on the sample key (a fixed-ratio or FR 4 schedule) were required to turn off the sample. Sample offset was followed by a 0 -sec (actually about $0.1-\mathrm{sec}$ ) delay; then the comparison stimuli were presented. A single peck (FR 1) on either comparison key turned off both keys and, if the matching stimulus was pecked, produced grain reinforcement. A single peck on the odd comparison key produced the intertrial interval. This and subsequent conditions are summarized in Table 1.

Table 1

Order of Occurrence of Conditions in Experiment 1

\begin{tabular}{|c|c|c|c|c|c|c|c|}
\hline Condition & $\begin{array}{c}\text { Sample } \\
\text { Schedule }\end{array}$ & $\begin{array}{c}\text { Comparison } \\
\text { Schedule }\end{array}$ & $\begin{array}{c}\text { Delay } \\
\text { (seconds) }\end{array}$ & Condition & $\begin{array}{l}\text { Sample } \\
\text { Schedule }\end{array}$ & $\begin{array}{c}\text { Comparison } \\
\text { Schedule }\end{array}$ & $\begin{array}{c}\text { Delay } \\
\text { (seconds) }\end{array}$ \\
\hline 1 & FR4 & FR1 & 0 & 17 & FR4 & FR4 & 5 \\
\hline 2 & FR4 & FR4 & 0 & 18 & FR4 & FR16 & 5 \\
\hline 3 & FR4 & FR 16 & 0 & 19 & FR4 & FR1 & 6 \\
\hline 4 & FR 4 & FR1 & 1 & 20 & FR4 & FR4 & 6 \\
\hline 5 & FR 4 & FR4 & 1 & 21 & FR4 & FR16 & 6 \\
\hline 6 & FR4 & FR 16 & 1 & 22 & FR4 & FR 1 & 7 \\
\hline 7 & FR4 & FR1 & 2 & 23 & FR4 & FR4 & 7 \\
\hline 8 & FR4 & FR4 & 2 & 24 & FR4 & FR16 & 7 \\
\hline 9 & FR4 & FR 16 & 2 & 25 & FR4 & FR 1 & 8 \\
\hline 10 & FR4 & FR 1 & 3 & 26 & FR4 & FR4 & 8 \\
\hline 11 & FR 4 & FR4 & 3 & 27 & FR4 & FR16 & 8 \\
\hline 12 & FR4 & FR 16 & 3 & 28 & FR2 & FR1 & 10 \\
\hline 13 & FR4 & FR1 & 4 & 29 & FR4 & FR1 & 10 \\
\hline 14 & FR4 & FR4 & 4 & 30 & FR2 & FR1 & 10 \\
\hline 15 & FR4 & FR 16 & 4 & 31 & FR4 & FR1 & 10 \\
\hline 16 & FR4 & FRI & 5 & & & & \\
\hline
\end{tabular}


During the next two blocks of 10 sessions, the sample schedule and delay duration were unchanged. In the first of these blocks, the first comparison keypeck turned off the other comparison key. An additional three pecks were required to produce reinforcement and/or the intertrial interval. Since a total of four pecks were required, this schedule was designated as FR 4 . In the next block of sessions, 16 (FR 16) pecks were required. Pecking the dark comparison key had no effect.

In the following sessions, the sample schedule was kept at FR 4 and the delay was increased, in 1 -sec increments, to $8 \mathrm{sec}$. During the delay interval, the chamber was dark and keypecking had no consequences. At each delay, the FR 1, FR 4, and FR 16 comparison schedules were in effect for 10 sessions, presented in that order.

During the last four 10-session blocks of the experiment, the delay was set at $10 \mathrm{sec}$ and the comparison schedule was set at FR 1. During the first and third blocks, the sample schedule was FR 2; during the second and fourth blocks, the sample schedule was FR 4.

In each session, the number of trials completed and the number of trials on which the matching comparison was pecked first were recorded and used to calculate matching accuracy. For the purpose of analysis, data from the last three sessions of each condition were used.

\section{Results}

Figure 1 shows matching accuracy as a function of delay. These data are averages across comparison $F R$ schedules for 0,1 , and $2 \mathrm{sec} ; 3,4$, and $5 \mathrm{sec}$; and 6,7 , and $8 \mathrm{sec}$. Midpoints of the delay interval groupings are shown on the abscissa. Figure 2 shows matching accuracy as a function of comparison FR value. These data are averages across the different delay intervals. Figure 3 shows matching accuracy as a function of sample FR value. These data are averages across the two presentations of FR 2 and FR 4 .

As these figures show, three main effects were found. First, matching accuracy decreased as the delay was increased. Second, matching accuracy decreased as the value of the comparison FR schedule was increased. Third, matching accuracy increased as the value of the sample FR schedule was increased.

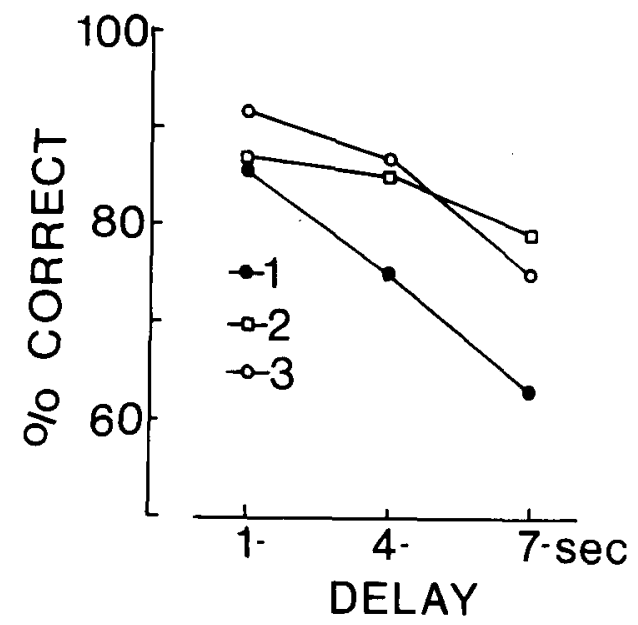

Figure 1. Matching accuracy (percent correct) for Birds 1, 2 , and 3 in Experiment 1 as a function of delay interval duration. Midpoints of delay interval grouping, in seconds, are shown on the abscissa.

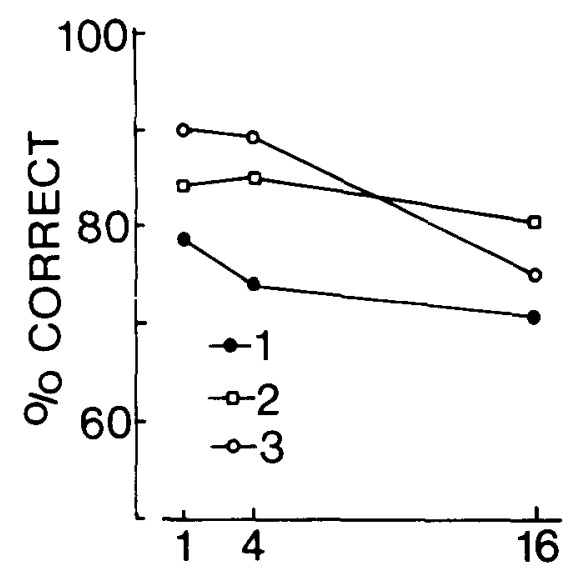

COMPARISON FR

Figure 2. Matching accuracy (percent correct) for Birds 1, 2, and 3 in Experiment 1 as a function of comparison FR values.

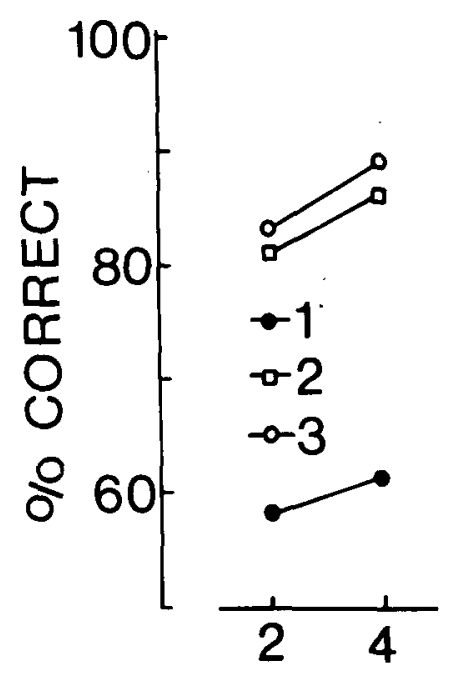

\section{SAMPLE FR}

Figure 3. Matching accuracy (percent correct) for Birds 1, 2, and 3 in Experiment 1 as a function of sample FR values. $A$ 10-sec delay was used and a comparison FR 1.

These observations were confirmed by 3 (subjects) by 3 (delay groupings) by 3 (comparison FR schedules) randomized block factorial analysis of variance and a repeated measures (sample FR 2 vs. sample FR 4) $t$ test. Matching accuracy was higher for sample FR 4 than for sample FR $2[\mathrm{t}(2)=18.3, \mathrm{p}<.01]$. Subjects $[\mathrm{F}(2,16)=11.6, \mathrm{p}<.01]$, delay $[\mathrm{F}(2,16)=23.4$, $\mathrm{p}<.01]$, and comparison schedule $[\mathrm{F}(2,16)=7.9$, $\mathrm{p}<.01]$ effects were significant. The Delay by Comparison schedule interaction was not significant $[\mathrm{F}(4,16)<1]$.

\section{Discussion}

These results replicate the well-known effects of delay duration on DMTS (e.g., Blough, 1959) as well as Roberts' (1972) and Sacks et al's (1972) finding 
that larger sample FR schedules facilitate DMTS accuracy. The latter effect has been analyzed in terms of the fact that increases in sample FR value increase exposure to the sample and that longer sample exposures facilitate matching (e.g., Roberts \& Grant, 1976).

The finding that larger comparison response requirements adversely affect matching accuracy is consistent with results recently reported by Lydersen et al. (1977). These investigators found that accuracy of choosing the odd (rather than the matching) comparison was adversely affected by increasing response requirements. It is interesting to note that these investigators arranged the comparison FR schedules so that both comparisons remained on until the FR requirement on one key was met. Apparently, then, larger comparison FR values reduce accuracy regardless of the manner in which the response requirement is scheduled.

Why comparison FR schedules should have an adverse effect on matching accuracy is not readily clear. There are two obvious possibilities. Higher FR schedules as arranged in the present experiment involve longer delays to reinforcement and/or the intertrial interval. Thus, with higher-valued FR comparison schedules, reinforcement for choosing the matching comparison is delayed and might be expected to weaken matching.

Higher-valued FR schedules also produce an initial pause (cf. Ferster \& Skinner, 1957). Such a pause, if it occurred after the onset of the comparison stimuli, would have the effect of increasing the time between sample offset and choice and might be expected to have an effect similar to increasing the delay duration.

\section{EXPERIMENT 2}

This experiment was done to provide more information on why higher-valued FR comparison schedules have an adverse effect on matching accuracy.

\section{Method}

Subjects and Apparatus. Birds 2 and 3 from Experiment 1 were tested in the same apparatus as was used in Experiment 1.

Procedure. As this experiment was performed immediately after the completion of Experiment 1, no retraining on the DMTS procedure was necessary. The sample schedule was kept constant at FR 4 and the delay at $10 \mathrm{sec}$. The comparison schedule was varied during the four phases as follows: FR 2, FR 16, FR 2, and FR 16. The phases lasted for $21,21,15$, and 10 sessions, respectively. During three of the last sessions of the third and fourth phases, the following were recorded: latency to peck sample (time between sample onset and the first peck); time to complete the sample FR 4 schedule (time from first to fourth peck on the sample key); latency to peck comparison (time from end of delay and comparison onset to first peck on either comparison key); time to complete comparison ratio.

All other aspects of the procedure were similar to those arranged in Experiment 1.

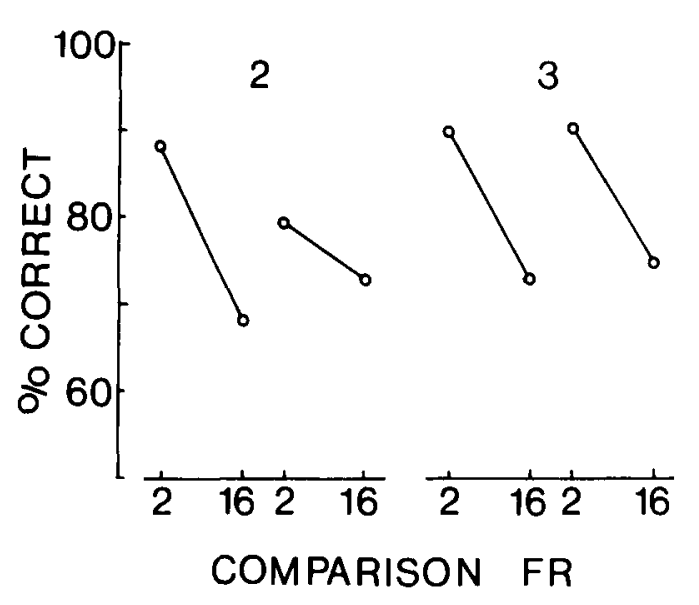

Figure 4. Matching accuracy (percent correct) for Birds 2 and 3 during the four phases of Experiment 2 when the comparison FR schedule was varied from 2 to 16.

\section{Results}

Figure 4 shows the effect on matching accuracy of varying the comparison FR schedule from 2 to 16 . These data are averages of the last seven sessions of a phase. As in Experiment 1, matching accuracy decreased as the value of the comparison FR was increased. This effect was confirmed by a 2 (subjects) by 2 (replications) by 2 (comparison schedules) randomized block factorial analysis of variance. The comparison schedule effect was significant $[F(1,3)=$ $34.2, p<.01]$, but the subjects effect $[F(1,3)=4.1$, $\mathrm{p}>.05]$, replications effect $[\mathrm{F}(1,3)<1.0]$, and Replications by Comparison Schedule interaction $[F(1,3)$ $=2.6, \mathrm{p}>.05]$ were not.

Latency to peck the sample did not vary systematically as the comparison FR schedule was varied. Average data for three sessions under FR 2 and FR 16, respectively, were 2.6 vs. $2.5 \mathrm{sec}$ for Bird 2 and 2.7 vs. $3.9 \mathrm{sec}$ for Bird 3. Slightly less time was taken to finish the sample FR when the comparison FR was 16 (1.3 and $1.1 \mathrm{sec}$ for Birds 2 and 3, respectively) than when it was 2 (1.6 and $1.5 \mathrm{sec}$, respectively). Both birds took slightly longer to peck a comparison stimulus when FR 16 was in effect (1.6 and $2.0 \mathrm{sec}$ for Birds 2 and 3, respectively) than when FR 2 was in effect $(0.9$ and $1.5 \mathrm{sec}$ for Birds 2 and 3 , respectively). While time to finish the FR 2 comparison ratio was for all practical purposes the same as the latency to choose a comparison, this was not the case when FR 16 was in effect. Then, Birds 2 and 3 took an average of 3.0 and $11.1 \mathrm{sec}$ to complete the FR.

\section{Discussion}

These results suggest that higher-valued comparison FR schedules may adversely affect DMTS accuracy in several ways. First, higher FR schedules increased 
latency to peck the comparison stimuli. This effect, which resembles the postreinforcement pause noted on simple FR schedules for food and other reinforcers (cf. Ferster \& Skinner, 1957), effectively lengthened the delay, a variable that is inversely related to matching accuracy (e.g., Blough, 1959).

Second, higher-valued comparison FR schedules shortened the time to finish pecking the sample. Such might have decreased the time the subjects were effectively exposed to the sample and thus might be expected to decrease accuracy, since matching accuracy decreases as exposure to the sample decreases (cf. Roberts, 1972).

Because both of the above effects were small in size, it seems unlikely that they would account totally or even in large part for the effects of comparison FR value on matching accuracy. For this reason, a third factor would seem to be implicated. The prime candidate would appear to be the delay between pecking the matching comparison stimulus and reinforcement. Since delayed reinforcement normally weakens behavior (e.g., Ferster \& Hammer, 1965), the longer delay between comparison choice and reinforcement, inherent when higher-valued FR schedules are programmed, could account for the adverse effects of higher FR schedule on matching accuracy. Because the evidence for such an effect found in the present experiment was correlational in nature, Experiment 3 was undertaken.

\section{EXPERIMENT 3}

In this experiment, an FR 1 comparison schedule was arranged and delay of reinforcement for pecking the matching comparison was varied.

\section{Method}

Subjects. Bird 3 from Experiments 1 and 2 and a new bird (Bird 4), experienced on DMTS but not on comparison FR, delay interval, or delay of reinforcement manipulations, were used.

Apparatus. The apparatus was the same as in Experiments 1 and 2 except that a BRS/LVE Model 1519 pigeon chamber was used.

Procedure. As both birds had prior DMTS training, no preliminary training was required.

The general procedure was the same as in Experiment 2 except that only single pecks on the sample and comparison keys were required. During the first and third phases of the experiment, the delay interval between sample offset and comparison onset was $0 \mathrm{sec}$; during the second phase, the delay was $5 \mathrm{sec}$. In the first phase, reinforcement for pecking the matching comparison was delayed during different blocks of sessions by $0,1.5,3.0$, and $6.0 \mathrm{sec}$. During the second phase, reinforcement for correct matches was delayed 0,3 , and $6 \mathrm{sec}$. During the third phase, reinforcement was delayed by 0,6 , and 9 sec. In all sessions, the first peck at either comparison key turned off both keys and rendered additional pecks ineffective. The intertrial interval, delay interval, and delay of reinforcement interval were spent in darkness. Each delay of reinforcement condition was in effect about 10 days. For the purpose of analysis, data from the last three sessions of each condition were used.

It should be noted that delay of reinforcement durations employed were within the range of times taken to complete the FR 16 comparison key requirements in Experiment 2.

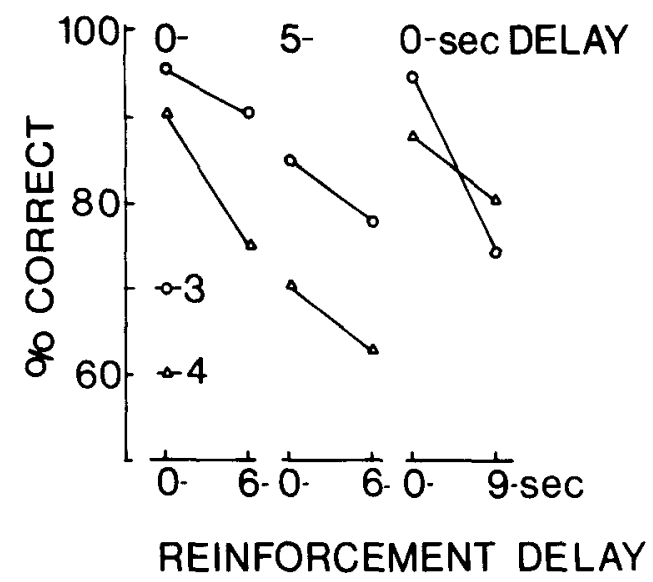

Figure 5. Matching accuracy (percent correct) for Birds 3 and 4 when delay interval was 0 or $5 \mathrm{sec}$ and when food reinforcement for correct choices was delayed from 0 to $9 \mathrm{sec}$.

\section{Results}

Figure 5 shows the effect on matching accuracy of varying the delay of reinforcement. Matching accuracy under the shortest $(0 \mathrm{sec})$ and longest $(6$ or $9 \mathrm{sec}$ ) delay of reinforcement in each phase is shown. The results are clear: delaying reinforcement for correct matches adversely affects matching accuracy. Data from the shortest and longest delay of reinforcement condition of each phase were subjected to a 2 (subjects) by 3 (phase) by 2 (delay of reinforcement) randomized block factorial analysis of variance. Delay of reinforcement was significant $[\mathrm{F}(1,5)=8.55, \mathrm{p}<.05]$, but subjects $[\mathrm{F}(1,5)=$ $5.17, \mathrm{p}>.05]$, phases $[F(2,5)=5.38, \mathrm{p}>.05]$, or Delay by Phase interaction $[F(2,5)<1.0]$ were not.

\section{Discussion}

The present results, which show that relatively short delays of reinforcement adversely affect matching accuracy, are consistent with the notion that larger comparison FR schedules harm matching accuracy by delaying reinforcement for choosing the matching comparison. In many respects, the results of the present experiment are similar to those obtained when reinforcement for a correct choice in a simultaneous discrimination is delayed. Cox and D'Amato (1977), for example, found that the accuracy of monkeys' choice of the correct member of a pair of stimuli (triangle vs. line) was adversely affected when reinforcement for correct choice was delayed by up to $128 \mathrm{sec}$

There are two alternate views regarding DMTS performance. Traditionally, delayed matching has been thought to involve a memory trace of the sample which weakens over time and which must be recalled at the time of choosing between the comparisons. A more recent view proposes that DMTS performance reflects "discrimination" rather than "memory" processes (cf.D'Amato \& Cox, 1976). According to this view, the animal, when faced with 
the comparison stimuli, does not recall sample information from memory but, rather, makes a discrimination as to which of the comparison stimuli was last seen. From this position, errors arise not from an inability to remember the sample but from an inability to discriminate which of two remembered stimuli was most recently seen as the sample. The similarity of the effects of delayed reinforcement in DMTS and simultaneous discrimination procedures tends to support the view that DMTS is a discriminative task.

The effect of manipulating the comparison ratio schedules is also consistent with this line of analysis. While the results of Lydersen et al. (1977) are easily amenable to a memory interpretation-larger ratios in their procedure may have simply increased the effective delay or "retention" interval-this is not the case with the present results. If the bird remembers the sample well enough to choose accurately when the comparison ratio is small, why cannot this information be recalled when larger comparison ratios are scheduled, when the only difference between the two schedules is the fact that additional pecks after the choice is made are required?

\section{REFERENCES}

Blough, D. S. Delayed matching in the pigeon. Journal of the Experimental Analysis of Behavior, 1959, 2, 151-160.

Boren, M. C. P. Fixed-ratio and variable-ratio schedules of brief stimuli in second-order schedules of matching to sample. Journal of the Experimental Analysis of Behavior, 1973, 20, 219-233.

Catania, A. C. Concurrent operants. In W. K. Honig (Ed.), Operant behavior: Areas of research and application. New York: Appleton-Century-Crofts, 1966. Pp. 213-270.

Cox, J. K., \& D'Aмato, M. R. Disruption of overlearned discriminative behavior in monkeys (Cebus apella) by delay of reward. Animal Learning \& Behavior, 1977, 5, 93-98.
D'Aмato, M. R., \& Cox, J. K. Delay of consequences and short-term memory in monkeys. In D. C. Medin, W. A. Roberts, \& R. T. Davis (Eds.), Processes of animal memory. Hillsdale, N.J: Erlbaum, 1976. Pp. 49-78.

Ferster, C. B., \& Hammer, C. Variables determining the effects of delay of reinforcement. Joumal of the Experimental Analysis of Behavior, 1965, 8, 243-254.

Ferster, C. B., \& Skinner, B. F. Schedules of reinforcement. New York: Appleton-Century-Crofts, 1957.

FERSTER, C. B. Intermittent reinforcement of matching to sample in the pigeon. Joumal of the Experimental Analysis of Behavior, $1960,3.259-272$.

KELLEHER, R. T. Chaining and conditioned reinforcement. In W. K. Honig (Ed.), Operant behavior: Areas of research and application. New York: Appleton-Century-Crofts, 1966. Pp. 160-212.

Lydersen, T., Perkins, D., \& Chairez, H. Effects of fixed-ratio sample and choice response requirements upon oddity matching. Journal of the Experimental Analysis of Behavior, 1977, 25, 97-101.

MAKI. W. S., JR. Sustained attention: Stimulus control determined by schedule of cue production interacting with cue duration. Animal Learning \& Behavior, 1975, 3, 312-316.

Maki, W. S.. Jr.. Gillund, G.. Hauge, G., \& Siders, W. A. Matching to sample after extinction of observing responses. Journal of Experimental Psychology: Animal Behavior Processes, 1977, 3, 285-296.

Nevin, J. A., Cumming, W. W., \& Berryman, R. Ratio reinforcement of matching behavior. Journal of the Experimental Analysis of Behavior, 1963, 6, 149-154.

Roberts, W. A. Short-term memory in the pigeon: Effects of repetition and spacing. Journal of Experimental Psychology, 1972, 94, 74-83.

Roberts, W. A., \& Grant, D. S. Studies of short-term memory in the pigeon using the delayed matching to sample procedure. In D. L. Medin, W. A. Roberts, \& R. T. Davies (Eds.), Processes of animal memory. Hillsdale, N.J: Erlbaum, 1976. Pp. 79-112.

SaChs, R. A., Kamil. A. C., \& MaCK, R. The effects of fixed-ratio sample requirements on matching to sample in the pigeon. Psychonomic Science, 1972, 26, 291-293.

Wilkie, D. M., \& Wilson, C. S. Control of pigeons' pecking by trace stimuli. Joumal of the Experimental Analysis of Behavior, 1977, 27, 293-299.

(Received for publication July 21, 1977; revision accepted February 10, 1978.) 